\title{
Synthesis and Application of Azo Disperse Reactive Dyes derived from p-Aminobenzaldehyde
}

\author{
Iyabo Fasansi, Kasali Ademola Bello, Mohammed Kabir Yakubu \\ Department of Textile Science and Technology, Ahmadu Bello University, Zaria, Nigeria.
}

\begin{abstract}
Disperse reactive dyes were synthesized by diazotizing p-aminobenzaldehyde and coupling with different substituted pyridones and 2-naphthol. The dyeing performance of the dyes was assessed on polyester, nylon, cotton and wool fabrics. The dyes obtained gave various shades of yellow with good depth, brightness and leveling properties on the fabrics. The dyed fabric showed fairly good to very good light fastness and very good to excellent fastness to washing, hot pressing and rubbing. The dyebath exhaustion on the polyester, nylon, wool and cotton fabrics was found to be very good and fixation on wool was better than on cotton fabric.
\end{abstract}

Keywords: p-aminobenzaldehyde; pyridone; disperse-reactive dyes; exhaustion; fixation; polyester, nylon, wool.

\section{INTRODUCTION}

The development of disperse dyes for dyeing secondary cellulose acetate fibres in the early 1920s was a major technological breakthrough. The major use of this dye today is for the coloration of polyester, the most important group of synthetic fibres ${ }^{1}$. Disperse dyes are used in aqueous dyebaths in the form of fine dispersions, because their solubility in water is very low, even at high dyeing temperatures ${ }^{2}$. In the conventional disperse dyeing of polyester, dispersing agents are usually added to increase the dispersion stability and solubility of disperse dyes. However, after the dyeing process is finished, they are not adsorbed onto polyester and discharged as effluents with the residual dyeing liquor, which increases the $\mathrm{COD}$ and $\mathrm{BOD}$ values of the effluent ${ }^{3-4}$.

It is widely known that the presence of an aldehyde group in a dye molecule renders the dye capable of reacting with the free functional groups of the wool keratin, or with the hydroxyl group of the cellulose $^{5-6}$. Azo dyes containing aldehyde group can thus be considered as reactive dyes ${ }^{7}$. In this paper, we report a series of azo dyes containing an aldehyde group which are capable of reacting with polyamide, cellulose, and wool giving good fixation and fastness properties.

\subsection{Materials and apparatus}

\section{EXPERIMENTAL}

All the chemicals used in the synthesis of the dyes and intermediates were of analytical grade and were used without purification. Melting points were determined by the open capillary method using the Gallenkamp melting apparatus. The visible absorption spectra were measured using Jenway $6405 \mathrm{UV} / \mathrm{Vis}$ spectrophotometer, IR was measured and recorded in $\mathrm{KBr}$ pellets using the FTIR-8400S Fourier Transform Infra-red Spectrometer, and GCMS using the GCMS-QP2010 PLUS SHIMDAZU Japan. The rubbing fastness test was carried out with a Crockmeter.

\subsection{Synthesis of p-amino benzaldehyde}

To $600 \mathrm{ml}$ of distilled water in a beaker was added $30 \mathrm{~g}(0.125 \mathrm{~mol}$. $)$ of sodium sulphide monohydride, $15 \mathrm{~g}$ sulphur and $27 \mathrm{~g}(0.67 \mathrm{~mol}$.) sodium hydroxide. The mixture was heated on a steam bath for 15-20 minutes with occasional stirring and then poured into a round-bottomed flask containing hot solution of $50 \mathrm{~g}(0.36 \mathrm{~mol}$.) of pnitrotoluene in $300 \mathrm{ml}$ of $95 \%$ ethanol. The mixture was refluxed for three hours under heat. The resulting clear but deep red solution was steamdistilled and stopped when the distillate was clear. The residue was rapidly chilled in an ice bath with occasional vigorous shaking and stirring to induce crystallization ${ }^{8}$.

\subsection{Synthesis of pyridone derivatives}

A mixture of $(0.1$ mole, $11.3 \mathrm{~g})$ ethylcyanoacetate, $(28.2 \mathrm{ml})$ and $(0.3 \mathrm{~mol}, 10.5 \mathrm{~g})$ ethylamine $(72 \mathrm{ml})$ were stirred until a clear solution was obtained and $(0.1 \mathrm{~mol} ., 13.0 \mathrm{~g})$ ethylacetoacetate was added. The mixture was refluxed at $110^{\circ} \mathrm{C}$ for 9 hours. The solution was diluted with water $(400 \mathrm{ml})$ and acidified with hydrochloric acid to give a white solid. This was filtered and washed with water. The process was repeated by replacing ethylamine with butylamine and dedocylamine respectively to obtain other pyridone derivatives. 


\subsection{Diazotization of p-aminobenzaldehyde}

P-Aminobenzaldehyde $(2.42 \mathrm{~g}, 0.02 \mathrm{~mol})$ was added to a mixture of acetic acid $(24 \mathrm{ml})$ and water $(6 \mathrm{ml})$ and cooled with stirring in a ice bath. Sodium nitrite $(1.5 \mathrm{~g}, 0.021 \mathrm{~mol})$ dissolved in water $(10 \mathrm{ml})$ was added in portion within thirty minutes and then concentrated hydrochloric acid $(10 \mathrm{ml})$ was added immediately. The mixture was left in the ice bath for 15 minutes and the excess nitrous acid destroyed by adding small amount of urea.

\subsection{Coupling diazotized p-aminobenzaldehyde with Pyridone}

A solution of the coupling component (0.02mole) was dissolved in $5 \mathrm{mls}$ of $2 \%$ stock solution of sodium hydroxide, $50 \mathrm{~g}$ of crushed ice was added to the solution. The diazonium salt of $\mathrm{p}$ aminobenzaldehyde was added in portion into the solution with constant stirring for over 30 minutes, the reaction was allowed to proceed for another one hour. The dye produced was filtered and dried in the oven at $50^{\circ} \mathrm{C}$. The final product was recrystallized from ethanol.

\subsection{Dyeing of Polyester}

The dye baths of liquor ratio 50:1 were prepared by using $2 \%$ on weight of fabric from $1 \%$ stock solution of the dye with a dispersol-levelling agent $\left(1 \mathrm{~g}^{-1}\right.$ litre $)$ and $5 \%$ phenol as carrier. The $\mathrm{pH}$ value of the bath was adjusted to $4-5$ with acetic acid (10\%). The polyester fabrics, previously wetted, were placed into the liquor at $25^{\circ} \mathrm{C}-30^{\circ} \mathrm{C}$. The temperature was raised to $100^{\circ} \mathrm{C}$ at the rate of $2^{\circ} \mathrm{C} / \mathrm{min}$, and dyeing continued for $60 \mathrm{~min}$. After cooling, reduction clearing of the dyed fabrics was carried out in a solution of sodium hydroxide $(2 \mathrm{~g} / \mathrm{L})$ and dispersing agent $(1.5 \mathrm{~g} / \mathrm{L})$ at $60^{\circ} \mathrm{C}$ for $30 \mathrm{mins}$ and then washed and dried. Percentage exhaustion was calculated to determine the dye absorption unto the fabric.

\subsection{Dyeing of nylon}

The Nylon fabric was dyed following the same procedure as in the dyeing of polyester but without using a carrier.

\subsection{Dyeing of wool}

$1 \%$ stock solution of each dye was prepared; a dye bath of liquor ratio of 50:1 was used with $2 \%$ shade on weight of fabric (o.w.f). The dyeing was carried out at $\mathrm{pH}$ of $3-4$, at $70^{\circ} \mathrm{C}$ for 1 hour after which the solution was made alkaline using sodium carbonate for fixation of the dyes into the fabric

\subsection{Dyeing of cotton}

$1 \%$ stock solution of each dye was also prepared, a dye bath of liquor ratio of 50:1 was used with $2 \%$ shade on weight of fabric (o.w.f) at $70^{\circ} \mathrm{C}$ using $25 \mathrm{~g} / \mathrm{L}$ of salt and at $\mathrm{pH} 8$ for 1 hour.

\subsection{Determination of \% Exhaustion and Fixation \\ Percentage exhaustion of the dyes was} calculated by taking the optical density of the dyebath before dyeing and after the dyeing and from the values obtained the \% exhaustion and fixations were calculated using the following formula:

$$
\% \text { Exhaustion }=\frac{O D_{1}-O D_{2}}{O D_{1}} \times 100
$$

where $\mathrm{OD}_{1}=$ Optical density before dyeing

$\mathrm{OD}_{2}=$ Optical density after dyeing

$$
\% \text { Fixation }=\frac{O D_{1}-O D_{2}-\Delta}{O D_{1}} \times 100
$$

where $\Delta$ is the optical density of the dye striped from the dyed fabric

\subsection{Fastness Tests}

The washing fastness, light fastness, hot pressing and rubbing fastness tests were carried out on each dyed fabric. The wash fastness test was carried out using the ISO number 4 method, the light fastness test was carried out under natural day light and assessed using 8 blue wool standard, the hot pressing was carried out using ISO standard and the rubbing fastness test was carried out using crockmeter (Atlas) in ISO standard ${ }^{9}$.

\author{
III. RESULTS AND DISCUSSION \\ 3.1 Synthesis of Intermediates and Dyes \\ P-Aminobenzaldehyde was synthesized by \\ following the reaction steps in Scheme 1. In this \\ Scheme, mixture of crystalline sodium sulphide \\ monohydrate, flowers of sulfur and sodium \\ hydroxide pellets in water was heated on a steam \\ bath with occasional stirring and then poured into \\ hot solution of p-nitrotoluene in $95 \%$ ethanol under \\ reflux. The resulting solution was rapidly steam- \\ distilled. The residue in the flask is diluted with
}


hot water and shilled in an ice bath with vigorous shaking to induce crystallization. Golden yellow crystals of p-aminobenzaldehyde are colleted by filtration.

1-Substituted-2-hydroxy-4-methyl-5-cyano-6-

pyridones $(4 a-4 c)$ were prepared from a mixture of ethylcyanoacetate (1), ethylacetoacetate (2) and amines $(3 a-3 c)$ in ethanol under reflux as shown in Scheme 2. p-Aminobenzaldehyde was diazotized using hydrochloric acid and sodium nitrite at $0^{\circ}-5^{\circ} \mathrm{C}$ and the diazonium salts coupled with pyridones $(4 \mathrm{a}-4 \mathrm{c})$ at $\mathrm{pH} 3-4$ to give the 1 substituted 3-(p-substituted phenylazo)-6-pyridone dyes $(5 a-5)$ as shown in Schemes 3 and 4 . Dye (5) was synthesized by coupling the diazonium salt with 2-naphthol. The structures of the pyridones were confirmed by mass spectrometry and IR while the structures of the dyes were confirmed by IR. The physical characteristics of the intermediates and dyes are summarized in Table 1.<smiles>Cc1ccc([N+](=O)[O-])cc1</smiles>

Scheme 1: Synthesis of p-Aminobenzaldehyde<smiles>[SiH]=[SiH]</smiles>

(1)

$$
\begin{aligned}
\mathrm{R}(\mathrm{a}) & =\mathrm{C}_{2} \mathrm{H}_{5} \\
\text { (b) } & =\mathrm{C}_{4} \mathrm{H}_{9} \\
\text { (c) } & =\mathrm{C}_{12} \mathrm{H}_{25}
\end{aligned}
$$

Scheme 2: Synthesis of Py ridones<smiles>[R]n1c(O)cc(C)c(C#N)c1=O</smiles>

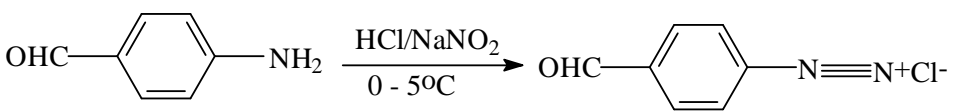

Scheme 3: Diazotization of p-Aminobenzaldehy de<smiles>[R]n1c(O)c(/N=N/c2ccc(C=O)cc2)c(C)c(C#N)c1=O</smiles><smiles>O=Cc1ccc(N=Nc2c(O)ccc3ccccc23)cc1</smiles>

(5)

Scheme 4: Synthesis of pyridone dyes $(5 a-5 c)$

\subsection{Physical Characteristics of the Intermediates}

intermediates and dyes are summarized in Table and Dyes The physical characteristics of the

1. Table 1: Physical Characteristics of the Intermediates and Dyes

\begin{tabular}{|l|l|l|l|l|}
\hline $\begin{array}{l}\text { Intermediate and } \\
\text { dye No }\end{array}$ & Molar mass g/mol & Melting point $\left.\mathbf{(}^{\mathbf{0}} \mathbf{C}\right)$ & Yield (\%) & $\begin{array}{l}\text { Colour of the } \\
\text { crystal }\end{array}$ \\
\hline $\mathbf{( 4 a )}$ & 178 & $244-246$ & 83 & White \\
\hline $\mathbf{( 4 b )}$ & 206 & $136-138$ & 75 & White \\
\hline $\mathbf{( 4 c )}$ & 318 & $76-79$ & 79 & White \\
\hline $\mathbf{( 5 a )}$ & $274-275$ & 70 & Yellow \\
\hline $\mathbf{( 5 b )}$ & 310 & $200-202$ & 86 & Yellow \\
\hline $\mathbf{( 5 c )}$ & 338 & $118-129$ & 60 & Yellow \\
\hline$(\mathbf{6})$ & 450 & $157-158$ & 68 & Reddish brown \\
\hline
\end{tabular}

3.3 Infrared Spectral of Intermediates and DyesThe results obtained from the Infrared spectral analysis are shown in Table 2 
Table 2: Infrared Spectra of the Intermediates and Dyes

\begin{tabular}{|l|l|l|l|l|l|l|l|l|l|}
\hline Funtional group & ArC-C & ArC-H & CN & C=C & C=O & ArN-H & OH & CHO & N=N \\
\hline Tye of vibration & Stretch & Bend & Stretch & Stretch & Stretch & Bend/stretch & Stretch & Stretch & Stretch \\
\hline $\mathbf{( 4 a )}$ & 1420 & 823 & 2201 & 1089 & 1622 & - & 3423 & - & - \\
\hline $\mathbf{( 4 b )}$ & 1422 & 825 & 2199 & 1039 & 1575 & - & 3425 & - & - \\
\hline $\mathbf{( 4 c )}$ & 1420 & 827 & 2200 & 1046 & 1601 & - & 3426 & - & - \\
\hline $\mathbf{( 5 a )}$ & 1417 & 806 & 2225 & 1157 & 134 & 1516 & 3430 & 1422 & $\mathbf{1 5 7 8}$ \\
\hline $\mathbf{( 5 b )}$ & 1416 & 808 & 2223 & 1019 & 1634 & 1508 & 3448 & 1480 & $\mathbf{1 5 7 7}$ \\
\hline $\mathbf{( 5 c )}$ & 1416 & 799 & 2225 & 1021 & 1637 & 1514 & 3462 & 1500 & $\mathbf{1 5 7 6}$ \\
\hline $\mathbf{( 6 )}$ & 1421 & 872 & - & 1047 & - & - & 3469 & 1510 & $\mathbf{1 5 2 2}$ \\
\hline
\end{tabular}

From the results in Table 2, all the synthesized pyridone based coupling component gave absorption peaks due to aromatic $\mathrm{C}=\mathrm{C}$ stretching vibration band at $1422-1420 \mathrm{~cm}^{-1}$, aromatic $\mathrm{C}-\mathrm{H}$ bending vibration band at $827-823$ $\mathrm{cm}^{-1}$, CN stretching vibration at 2201-2199 $\mathrm{cm}^{-1}$, $\mathrm{C}=\mathrm{O}$ stretching vibration at $1622-1575 \mathrm{~cm}^{-1}$ and $\mathrm{OH}$ stretching vibration at $3884-3433 \mathrm{~cm}^{-1}$. As can also be seen from the infra-red spectra results in Table 2, all the dyes gave absorption peaks due to azo group , $-\mathrm{N}=\mathrm{N}$ - stretching vibration at 1578$1421 \mathrm{~cm}^{-1}$, aromatic C-C stretching vibration band at $1421-1416 \mathrm{~cm}^{-1}$, aromatic $\mathrm{C}-\mathrm{H}$ bending vibration band at $872-799 \mathrm{~cm}^{-1}, \mathrm{CN}$ stretching vibration at $2225-2223 \mathrm{~cm}^{-1}, \mathrm{C}=\mathrm{C}$ stretching vibration band at $1157-1019 \mathrm{~cm}^{-1}, \mathrm{C}=\mathrm{O}$ stretching vibration at 1637 $1634 \mathrm{~cm}^{-1}$, aromatic amine $(\mathrm{NH})$ stretching vibration at $1516-1508 \mathrm{~cm}^{-1}$ and $\mathrm{OH}$ stretching vibration at $3469-3430 \mathrm{~cm}^{-1}$.

\subsection{Visible Absorption Spectra of the Dyes}

The visible absorption spectra of the dyes are measured in different solvents and extinction coefficient calculated in DMF. The results obtained are summarized in Table 3.

Table 3: Visible Absorption Spectra of the Dyes

\begin{tabular}{|l|l|l|l|l|l|}
\hline Dye No. & $\begin{array}{l}\square_{\mathbf{m a x}} \mathbf{1 0}^{\mathbf{4}} \mathbf{L m o l}^{-} \\
\mathbf{c m}^{-\mathbf{1}} \mathbf{\text { in } \mathbf { D M F }}\end{array}$ & Ethanol $\square_{\max }$ & $\begin{array}{l}\text { Ethanol + HCl } \\
\square_{\max }\end{array}$ & DMF $\square_{\max }$ & $\begin{array}{l}\text { Change } \\
\square_{\max }\end{array}$ \\
\hline $\mathbf{( 5 a )}$ & 3.8 & 432 & 435 & 437.5 & $\mathbf{+ 3}$ \\
\hline $\mathbf{( 5 b )}$ & 2.2 & 457 & 435 & 442 & $\mathbf{- 2 2}$ \\
\hline $\mathbf{( 5 c )}$ & 2.3 & 485 & 435 & 442 & $\mathbf{- 5 0}$ \\
\hline $\mathbf{( 6 )}$ & 3.0 & 420 & 486 & 486 & $\mathbf{+ 6 6}$ \\
\hline
\end{tabular}

The visible absorption properties of the dyes were measured in ethanol, ethanol $+\mathrm{HCl}$ and $\mathrm{DMF}$ respectively, and the results are summarized in Table 3. From Table 3, it can be seen that the bathochromicity increases in the order of dyes $(5 \mathrm{c})>$ $(5 b)>(5 a)$. This may be attributed to the longer alkyl chain length attached to the coupling component in dyes (5c), (5b), and (5a) which are coupled with pyridone derivatives. Hence, dye $(5 c)$ with 1 -dedocy2-hydroxyl-4-methyl-5-cyano-6-pyridone coupling component contains more alkyl chain length and thus has the maximum absorption wavelength of $485 \mathrm{~nm}$ which is more bathochromic than dye (5b) with coupling component 1-butyl-2-hydroxyl-4-methyl-5cyano-6-pyridone which absorbed at 457 and dye (5a) with 1-ethyl-2-hydroxyl-4-methyl-5-cyano-6pyridone with $432 \mathrm{~nm}$ in ethanol respectively. However dye (6) which was obtained by coupling with 2-naphthol, gave maximum absorption wavelength of $420 \mathrm{~nm}$ in the same solvent, which is hypsochromic when compared with dyes in series (5).

It can also be seen from in results in Table 3 that two of the dyes, dyes (5b) and (5c) showed negative solvatochromism as the wavelength tends to reduce with increasing polarity of the solvent. The maximum absorption wavelength values shifted to shorter wavelength when the solvent was changed from ethanol to DMF. This implies that the dye molecules have more polar ground state than the excited state and this will increase the energy difference between the ground and the excited states, thus leading to hypsochromic shift in the visible absorption region of the spectrum ${ }^{10}$. However, dyes (5a) and (6) showed positive solvatochromism. For example dye (5a) gave maximum absorption wavelength of $432 \mathrm{~nm}$ in ethanol, and $437.5 \mathrm{~nm}$ in DMF and similarly dye (6) gave maximum absorption wavelength of $420 \mathrm{~nm}$ in the same solvent and 486 $\mathrm{nm}$ in DMF, giving positive solvatochromism of 5.5 $\mathrm{nm}$ and $66 \mathrm{~nm}$ respectively. This means that dyes (5a) and (6) have more polar excited state than the group state and a polar solvent can stabilize this more than the ground state.

The effect of few drops of acids on ethanol solution of the dyes was also observed and the result are also summarized in Table 3. From the results obtained it can be deduced that dyes (6) and (5a) have positive halochromism as they absorbed at $420 \mathrm{~nm}$ 
and $432 \mathrm{~nm}$, respectively in neutral solution of ethanol and absorbed maximally at $486 \mathrm{~nm}$ and $435 \mathrm{~nm}$ respectively in acidic solution of ethanol, indicating a bathochromic shift of +66 and +3 , respectively. Dyes (5a) and (5b) showed negative halochromism absorbing at $457 \mathrm{~nm}$ and $485 \mathrm{~nm}$ in neutral solution of ethanol and $435 \mathrm{~nm}$ in acidic solution of the ethanol having hypsochromic shift $-22 \mathrm{~nm}$ and $-50 \mathrm{~nm}$, respectively. The shift may be attributed to the electron withdrawing strength of the substituent, if the electron withdrawing strength of the substituent is sufficiently high, zero or negative halochromism can be observed ${ }^{11}$.

The molar extinction coefficient of the dyes was calculated using DMF as solvents. The results obtained are shown in Table 3, and from the results, it can be concluded that the dyes posses high molar extinction coefficient. The higher molar extinction coefficients value of the dyes implies the probability for more electronic transition, the fact that they transmit more light in comparison to others and therefore have narrow absorption bands with sharp peaks $^{12}$.

\subsection{Dyeing and Fastness properties}

The synthesized dyes were applied to polyester, nylon 6,6, wool and cotton fabrics and the results are summarized in Table 4. The results in Table 4 indicate a higher percentage exhaustion on nylon 6,6 and polyester fabric as compared to wool and cotton. The dyes gave very good levelness and fibre penetration on all the fabrics used. The exhaustion was between $92 \%$ and $80 \%$ on polyester, between $88 \%$ and $80 \%$ on nylon 6,6 , between $89 \%$ and $70 \%$ on wool and between $79 \%$ and $76 \%$ on cotton fabrics. The higher percentage exhaustion in polyester fabric may be attributed to the presence of dispersing agents which assist in the reduction of particle size of dyes, facilitated reverse change from powder to dispersion when the dye bath was prepared and maintaining dispersion during dyeing. The percentage fixation values were higher in wool compared to cotton. The dyes gave excellent to very good wash fastness, good to fair light fastness, excellent fastness to hot press on nylon 6,6 and polyester fabrics and excellent to good rubbing fastness.

Wool, nylon and cotton dyed with the synthesized dyes showed no loss of dye when treated with warm pyridine and also with DMF-H2O (1:1) mixture. This confirmed the formation of covalent bond between the dye and the substrates. The dye fibre reaction leading to covalent bond and hydrolysis on wool is summarized as shown in Scheme $5^{13}$.

$$
\begin{aligned}
& \text { Dye }-\mathrm{CHO}+\text { Wool }-\mathrm{NH}_{2} \longrightarrow \text { Dye- } \mathrm{CH}=\mathrm{N}-\text { Wool }+\mathrm{H}_{2} \mathrm{O} \\
& \text { Dye }-\mathrm{CH}=\mathrm{N} \longrightarrow \text { Wool hydrolysis } \\
& \longrightarrow \mathrm{Dye}-\mathrm{CHO}+\text { Wool}-\mathrm{NH}_{2}
\end{aligned}
$$

Scheme 5: Reaction leading to covalent fixation and hydroly sis of the dyes

\begin{tabular}{|c|c|c|c|c|c|c|}
\hline \multirow[t]{2}{*}{ Dye No. } & \multirow{2}{*}{$\begin{array}{l}\% \text { exhaustion } \\
\text { on Polyester }\end{array}$} & \multirow{2}{*}{$\begin{array}{l}\% \text { exhaustion } \\
\text { on Nylon } 6,6\end{array}$} & \multicolumn{2}{|l|}{ Wool } & \multicolumn{2}{|l|}{ Cotton } \\
\hline & & & $\%$ exhaustion & $\%$ fixation & $\%$ exhaustion & \% fixation \\
\hline (5a) & 80 & 80 & 70 & 82 & 78 & 58 \\
\hline$(5 b)$ & 80 & 80 & 81 & 88 & 79 & 54 \\
\hline (5c) & 88 & 81 & 89 & 98 & 77 & 59 \\
\hline (6) & 92 & 88 & 72 & 80 & 76 & 60 \\
\hline
\end{tabular}

Table 4: Percentage Exhaustion and Fixation of Dyes on Different substrates

Table 5: Wash Fastness Properties of the Dyes

\begin{tabular}{|l|l|l|l|l|l|l|l|l|}
\hline Dye No. & \multicolumn{4}{l|}{ Change in colour } & \multicolumn{3}{l|}{ Staining of adjacent fabric } \\
\hline & Polyester & Nylon 6,6 & Wool & Cotton & Polyester & Nylon 6,6 & Wool & Cotton \\
\hline $\mathbf{( 5 a )}$ & 5 & 5 & $4-5$ & $4-5$ & 5 & $4-5$ & $4-5$ & $\mathbf{4 - 5}$ \\
\hline $\mathbf{5 b})$ & 5 & 5 & $4-5$ & $4-5$ & 5 & 5 & 4 & $\mathbf{4 - 5}$ \\
\hline $\mathbf{( 5 C )}$ & 5 & 5 & 5 & $4-5$ & 5 & 5 & 4 & $\mathbf{4 - 5}$ \\
\hline$(\mathbf{6})$ & 5 & 5 & 4 & 5 & 5 & 5 & 4 & $\mathbf{4 - 5}$ \\
\hline
\end{tabular}

Table 6: Light Fastness Properties of the Dyes

\begin{tabular}{|l|l|l|l|l|}
\hline Dye No. & Polyester & Nylon 6,6 & Wool & Cotton \\
\hline (5a) & 7 & 7 & 5 & $\mathbf{5}$ \\
\hline $\mathbf{5 b})$ & 7 & 6 & 6 & $\mathbf{6}$ \\
\hline $\mathbf{5 c})$ & 7 & 7 & 5 & $\mathbf{5}$ \\
\hline$(\mathbf{6})$ & 7 & 7 & 5 & $\mathbf{4}$ \\
\hline
\end{tabular}


Table 7: Rubbing Fastness Properties of the Dyes on Different Substrates

\begin{tabular}{|l|l|l|l|l|l|l|l|l|}
\hline & \multicolumn{3}{|l}{ Polyester } & Nylon & Wool & \multicolumn{3}{l|}{ Cotton } \\
\hline Dye No. & Dry & Wet & Dry & Wet & Dry & Wet & Dry & Wet \\
\hline$(\mathbf{5 a})$ & $4-5$ & $4-5$ & 5 & 5 & 5 & $4-5$ & 4 & $\mathbf{3 - 4}$ \\
\hline $\mathbf{( 5 b )}$ & $4-5$ & $4-5$ & 5 & 5 & 5 & 5 & $4-5$ & $\mathbf{4}$ \\
\hline $\mathbf{( 5 c )}$ & 5 & 5 & $4-5$ & $4-5$ & $4-5$ & 4 & $4-5$ & $\mathbf{4}$ \\
\hline$(\mathbf{6})$ & 5 & $4-5$ & 5 & $4-5$ & 5 & $4-5$ & 4 & $\mathbf{3 - 4}$ \\
\hline
\end{tabular}

Table 8: Hot Pressing Fastness of the Dyes on the Substrates

\begin{tabular}{|l|l|l|l|l|l|l|}
\hline Dye No. & \multicolumn{2}{l|}{ Polyester } & Nylon 6,6 \\
\hline & Dry & Damp & Wet & Dry & Damp & Wet \\
\hline $\mathbf{( 5 a )}$ & 5 & 5 & 5 & 5 & 5 & $\mathbf{5}$ \\
\hline $\mathbf{5 b})$ & 5 & 5 & 5 & 5 & 5 & $\mathbf{5}$ \\
\hline $\mathbf{5 c})$ & 5 & 5 & 5 & 4 & $4-5$ & $\mathbf{4 - 5}$ \\
\hline $\mathbf{( 6 )}$ & 4 & 4 & 4 & 5 & 5 & $\mathbf{5}$ \\
\hline
\end{tabular}

\section{CONCLUSION}

The dyes produced from coupling with the alkyl-2-hydroxy-4-methyl-5-cyano-6-pyridone groups and 2-naphthol showed disperse-reactive property. These dyes gave mostly yellow and orange colours. The remarkable degree of levelness after washing indicates good penetration and affinity of these dyes for the fabrics. Exhaustion and fixation of these dyes were very good and indicate that the dyes have good affinity for the fabrics. The dyes showed excellent fastness to washing, rubbing and hot pressing. The light fastness is excellent on polyester and nylon and good on wool and cotton fabrics.

\section{REFERENCES}

[1]. D. Broadbent, Basic Principles of Textile coloration; Society of Dyers and Colourists, (2001) 307.

[2]. C.R.Meena, Girendra, R.V.Adivarekar \& N.Sekar. Synthesis and Application of Vinylsulphone Disperse Reactive Dyes for Polyester. International Journal of ChemTech Research. 5(2) (2013) 585591.

[3]. Sekar N. and Deulgaonkar D.S. Recent developments in azo reactive dyes for wool. Colouration Technology. Vol. 53, issue 1, (2006) 82.

[4]. Sakoma K.J., Bello K. A. and Yakubu M. K., (2012). Synthesis of Some Azo Disperse Dyes from 1-Substituted 2Hydroxy-6-pyridone Derivatives and Their Colour Assessment on Polyester Fabric. Open Journal of Applied Sciences, Vol. 2, (2012) 54-59.

[5]. I.C. Watt and R. Morris, Text Res. J. 40 (1970) 952

[6]. R.N. Reddie and C.H. Nicholls, Text. Res J. 41 (1971) 303

[7]. S. Savel, J. Soc. Dyers Colourists 110
(1994) 241.

[8]. E. Campaigne, W.M. Budde and G.F. Schaefer. P-Aminobenzaldehye. Organic Syntheses, Cll Vol 4. (1963) 31

[9]. Standard Methods for the Assessment of Colour Fastness of Textiles (1955).

[10]. K.A. Bello. Near Infrared Absorbing Dyes. Ph.D. Thesis University of Leeds (1986).

[11]. A.A Tandama (2012). Synthesis of Triazinyl Dichloro and Monochloro Reactive Dyes and Their Application on Wool and Cotton Fabrics (Master of Science dissertation, Ahmadu Bello University, (2012).

[12]. K.J. Sakoma. Synthesis and application of Azo Disperse Dyes and their Assessment on Polyester Fabrics. M.Sc. Dissertation, Ahmadu Bello University, (2011).

[13]. N. Sekar and D.S. Deulgaonnkar. Synthesis of Azo Reactive Dyes Containing Adehyde Group. Asian Journal of Chemistry Vol 19, No. 4 (2007) 2565 2573. 